TI 2002-083/1

Tinbergen Institute Discussion Paper

\title{
A Monte Carlo Comparison between the Free Cash Flow and Discounted Cash Flow Approaches
}

\author{
Mehari Mekonnen Akalu' \\ Rodney Turner ${ }^{2}$
}

\footnotetext{
${ }^{\prime}$ Department of Marketing and Organisation, Faculty of Economics, Erasmus University Rotterdam, and Tinbergen Institute,

2 Department of Marketing and Organisation, Faculty of Economics, Erasmus University Rotterdam.
} 
Tinbergen Institute

The Tinbergen Institute is the institute for economic research of the Erasmus Universiteit Rotterdam, Universiteit van Amsterdam and

Vrije Universiteit Amsterdam.

Tinbergen I nstitute Amsterdam

Keizersgracht 482

1017 EG Amsterdam

The Netherlands

Tel.: +31.(0)20.5513500

Fax: $\quad+31 .(0) 20.5513555$

Tinbergen Institute Rotterdam

Burg. Oudlaan 50

3062 PA Rotterdam

The Netherlands

Tel.: $\quad+31 .(0) 10.4088900$

Fax: $\quad+31 .(0) 10.4089031$

Most TI discussion papers can be downloaded at

http://www.tinbergen.nl 


\title{
A Monte Carlo Comparison between the Free Cash Flow and Discounted Cash Flow Approaches
}

\author{
Mehari Mekonnen Akalu ${ }^{\mathrm{a}}$ and Rodney Turner ${ }^{\mathrm{b}}$
}

This version: 09 August 2002

\begin{abstract}
One of the debates in the capital budgeting model selection is between the free cash flow and DCF methods. In this paper an attempt is made to compare SVA against NPV model based on Monte Carlo simulations. Accordingly, NPV is found less sensitive to value driver variations and has got higher forecast errors as compared to SVA model.
\end{abstract}

JEL Classification: G30, G31, L6, L8, L9, M10, O22, O32

Key words: Capital budgeting, Investment appraisal, DCF methods, Project Analysis, Shareholder Value Analysis, Value Management Techniques

\footnotetext{
${ }^{a} \mathrm{PhD}$ candidate at the Tinbergen Institute, Erasmus University, Burg. Oudlaan 50, 3062 PA Rotterdam, the Netherlands (correspondence address).

${ }^{b}$ Professor of Project Management at the Faculty of Economic Sciences, Erasmus University, Burg. Oudlaan50, 3062 PA Rotterdam the Netherlands. The authors would like to thank Dr. Richard Paap, Econometric Institute of the Erasmus University, for his comments and suggestion in the development of this paper.
} 


\section{A Monte Carlo Comparison between the Free Cash Flow and Discounted Cash Flow Approaches}

\section{Introduction}

There are three groups of investment appraisal models used to gauge the profitability of a project. These are the traditional techniques, such as the pay back period and the accounting rate of return; the discounted cash flow methods (DCF), such as the net present value (NPV) and the internal rate of return (IRR); and the value based management models, such as the shareholder value analysis, the economic value added and the cash value added. The second and the third groups have a number of common elements.

However, there is a continuous debate on whether the value based management models measure the value of a project better than the DCF methods. Arguments in each group are diverse. Scholars such as Kennedy (2000), in his book, The End of Shareholder Value, argued the irrelevance of the value based management models such as the SVA. However, Mills and Print (1995), have explained that the two groups of models are complementary. Others, such as Rappaport (1998) and Tully (1993) are in favour of the value-based management models. In addition, attempts have also been made to reconcile the variation between the two groups (Shrieves and Wachowicz, 2001; Hartman, 2000).

This paper focuses on the two prominent and widely applied appraisal models: the net present value (NPV) and the shareholder value analysis (SVA). The paper attempts to compare the performances of the two models and investigate their impact on shareholder value. In addition, it is intended to look into the viability of the SVA model for project appraisal and control. Lastly, this analysis is also expected to shade a light on the controversy between the free cash low measures and DCF technique raised by scholars in earlier researches.

The paper is structured as follows. Section two describes the two models followed by simulation methodology in section three. Section four, five and six contain the simulation results, validation procedure and the sensitivity of the models respectively. Finally, section seven concludes the paper. 


\section{Models}

The NPV and SVA models are neither in the same category of investment appraisal techniques nor do they follow similar procedure of analysis. They do have different source of inputs and so does their relationship with company accounts and accounting information. A further important distinction between the two models is their constituent variables. Accordingly, the SVA has more value drivers than the NPV model. However, the two models follow the same approach, discounted cash flow, at arriving a given solution. For the purpose of this simulation, the SVA and the NPV models take the following forms (equation 1 and 2 respectively).

$$
\begin{aligned}
& \text { (1) } \quad \mathrm{SVA}=\sum_{\mathrm{t}=1}^{\mathrm{T}}\left(\frac{\theta^{\mathrm{i}}{ }_{\mathrm{t}}}{(1+\alpha)^{\mathrm{t}}}\right)+\frac{\theta_{\mathrm{T}}}{\alpha(1+\alpha)^{\mathrm{T}-1}}+\theta_{\text {inv }}-\eta \\
& \theta_{\mathrm{t}}=\mathrm{OCF}_{\mathrm{t}}-\mathrm{OPC}_{\mathrm{t}}-\mathrm{IFC}_{\mathrm{t}}-\mathrm{IWC}_{\mathrm{t}}-\mathrm{IRC}_{\mathrm{t}}
\end{aligned}
$$


(2)

$$
\begin{gathered}
\mathrm{NPV}=\sum_{\mathrm{t}=1}^{\mathrm{T}}\left(\frac{\theta_{\mathrm{t}}}{(1+\alpha)^{\mathrm{t}}}\right)-\mathrm{I}-\eta \\
\theta_{\mathrm{t}}=\mathrm{OCF}_{\mathrm{t}}-\mathrm{OPC}_{\mathrm{t}} \\
\mathrm{I}=\mathrm{IFC}+\mathrm{IWC}+\mathrm{IRC}
\end{gathered}
$$

Where,

$\begin{array}{ll}\theta_{\mathrm{t}} & \text { free (net) cash flow for } \text { i }^{\text {th }} \text { simulation } \\ \theta_{\text {inv }} & \text { cash flow from temporary investments } \\ \theta_{\mathrm{T}} & \text { terminal cash flow } \\ \eta & \text { market value of debt } \\ \mathrm{I} & \text { investment } \\ \text { IFC } & \text { incremental investment in fixed capital } \\ \text { IRC } & \text { incremental investment to replace the existing capital } \\ \text { IWC } & \text { incremental investment in working capital } \\ \text { OCF } & \text { operating cash flow distributed as OCF } \sim \text { NID }\left(\mu, \beta^{2}\right) \\ \mu & \text { the mean of the distribution } \\ \beta & \text { the variance of the distribution } \\ \text { OPC } & \text { operating cost } \\ \alpha & \text { cost of capital } \\ \mathrm{T}, \mathrm{t} & \text { time span (planning period) } \\ \mathrm{N}, \mathrm{i} & \text { number of simulations }\end{array}$

Note that the SVA model can take different forms. For instance, a new structure can be obtained by eliminating variables such as the terminal value and/ or the cash flow from temporary investments. However, in this simulation the general form is used.

In order to investigate the properties of the models, the expected values of SVA and NPV are computed as shown in equation (3) and (4). Where $\mathrm{E}$ is the expectation operator, the equations will be:

(3) $\quad \mathrm{E}(\mathrm{SVA})=\sum_{\mathrm{i}=1}^{\mathrm{N}}\left[\sum_{\mathrm{t}=1}^{\mathrm{T}} \frac{\theta^{\mathrm{i}} \mathrm{t}}{(1+\alpha)^{\mathrm{t}}}+\frac{\theta_{\mathrm{T}}}{\alpha(1+\alpha)^{\mathrm{T}-1}}\right]+\theta_{\text {inv }}-\eta$ 


$$
E[N P V]=\frac{1}{N} \sum_{i=1}^{N}\left[\sum_{t=1}^{T} \frac{\theta_{t}}{(1+\alpha)^{t}}\right]-I-\eta
$$

In the above equations, OCF is assumed a random continuous variable, where its realizations are normally distributed and the expected value of the realization is finite. Furthermore, $\theta_{\mathrm{t}}^{\mathrm{i}}$, is computed for each simulation; and $\theta_{\mathrm{T}}$, the average terminal value, is obtained by averaging all simulated values.

\section{Methodology}

Simulation is the process of designing a model for a real system to understand the behavior of a system or evaluate various strategies for the operation of a system (Oakshott, 1997, p. 121). It is based on statistical measures and predetermined probability distribution of random numbers (Gitman, 1997, p. 385). As described by Shubik and Brewer (1972, p.4), one of the reasons for doing simulation is to capture the robustness and richness of a real system represented by a model. Thus, simulation can be used to compare and contrast models based on their outcomes.

Simulation is essential when a system embodies elements of uncertainty. An area of such application is the capital budgeting decision, where the uncertainty of cash flow and discount factor is at a stake. In this regard, the method assists to evaluate the feasibility of a project before the actual operation begins and saves from expensive experiments. It can clearly indicate how sensitive is a project or its variables to the value of shareholders. Furthermore, it prevents from accepting a project based on constant value assumptions over its life span (Sartori and Smith, 1997).

Simulation has been applied in different areas of investment, such as project evaluation (Sartori and Smith, 1997, p.1), selections of mutually exclusive project (Eschenbach and Smith, 1992) and real estate investment appraisals (Kelliher and Mahoney, 2000). Although simulation is suitable to capture uncertainty in the real system, the method 
remains a complex process and poses problem of interpreting the distribution of the final value (Brealey and Myers, 2000, p. 270). Despite this problem, this paper follows the simulation approach to compare the two models.

\subsection{Assumptions}

A number of assumptions are considered to simulate data for a hypothetical company. Some of these assumptions are:

1. The models are assumed dynamic with some discrete event and discrete data values (Oakshott, 1997, pp. 122-129).

2. Except for the project random operating cash flow, all proportions of the input values are assumed to be deterministic (Appendix A).

3. The models assume constant growth in value drivers.

4. In addition, the original assumptions of the individual models are also taken into account.

\subsection{Data}

The length of project life affects the size of terminal value of the SVA model. Various scholars consider different life span in project analysis research. For instance, Finnegan (1999) had a 5-year data analysis with zero growth in terminal value. Mills (1998) has suggested a 5-year period with perpetual terminal cash flow over the competitive advantage period. Furthermore, Kelliher and Mahoney (2000) have used 10-years project life span in their simulation of a real estate project. Rappaport (1998) had both 5 and 10-year period analysis (p. 46). Following these arguments, 5, 10 and 15 years are considered for the initial simulation. However, most of the discussions are based on 10-year life span. In 
addition, cash flows are analysed at quarterly, semi-annually and yearly observations. All results are taken after $10000(\mathrm{~N}=10000)$ iterations.

\subsection{Software}

Various softwares are available to simulate quantitative dynamic models. This simulation is based on GAUSS for Windows Version 3.2.35 and program codes are constructed, for each model, using Gauss Programming Language ${ }^{1}$.

\section{Results}

The expected final value of the two models, for a hypothetical data, is depicted in Table 1. In this simulation, the term final value is defined as shareholder value (company value less external financing) and net NPV (NPV less any external financing) for respective models. Referring to Table 1, the NPV model results a negative expected final value for all periods.

Table 1: The Expected Final Value ${ }^{2}$

(Hypothetical data)

\begin{tabular}{||c|c|r|r|r||}
\hline \hline $\begin{array}{c}\text { Project } \\
\text { life } \\
\text { (Years) }\end{array}$ & Model & \multicolumn{3}{|c||}{ Period } \\
\cline { 2 - 5 } & & $\begin{array}{r}\text { Quarterly } \\
(\mathrm{Q})\end{array}$ & $\begin{array}{c}\text { Semiannually } \\
\text { (SA) }\end{array}$ & \multicolumn{1}{c||}{ Yearly } \\
\hline 5 & NPV & $(39.3)$ & $(54.2)$ & $(83.7)$ \\
\cline { 2 - 5 } & SVA & 36.8 & 27.9 & 10.1 \\
\hline 10 & NPV & $(165.8)$ & $(180.9)$ & $(210.9)$ \\
\cline { 2 - 5 } & SVA & 15.25 & 5.4 & $(14.3)$ \\
\hline 15 & NPV & $(347.3)$ & $(362.0)$ & $(391.4)$ \\
\cline { 2 - 5 } & SVA & 3.22 & $(7.32)$ & $(28.4)$ \\
\hline \hline
\end{tabular}

Another batch of simulation is also made based on real (part of the inputs) data set. This data is obtained from he results of shareholder value performance classification made by Akalu (2002a). In this classification, 126 companies are grouped into high, medium and poor performance categories. From this data set, four companies (two companies each from high

\footnotetext{
${ }^{1}$ Gauss is a Mathematical and Statistical System based matrix-programming language. The software is a product of Aptech Systems Inc (http://www.aptech.com/). Program codes can be obtained from the author.

${ }^{2}$ All values are in Euro and numbers in brackets means negative values.
} 
and low performance group) are taken to compare the two models based on their expected final outcome. The drivers included in this empirical simulation are the operating cost, OPC; the incremental fixed cost, IFC; incremental working capital, IWC, and investment in replacement capital, IRC (Appendix B). The discount factor and the market value of debt are assumed to be the same for all companies. Similar to the previous simulation, the OCF is a random variable. The results of 10-year semiannual simulations are depicted on Table 2.

Table 2: Expected final value

(Empirical data)

\begin{tabular}{||l|r|r||}
\hline \hline Companies & \multicolumn{1}{|c|}{ SVA } & \multicolumn{1}{c|}{ NPV } \\
\hline Company- A (High-01) & 358.17 & 740.34 \\
\hline Company- B (High-02) & 181.83 & 168.81 \\
\hline Company- C (Low-01) & 96.65 & $(213.56)$ \\
\hline Company- D (Low-02) & 17.57 & $(388.26)$ \\
\hline \hline
\end{tabular}

Except for company-A, the simulation outcome is consistent with the previous discussions. Similarly, in these simulations, the SVA overall performance, in terms of the amount of expected final value, is better than the NPV model.

\section{Model Validation}

After obtaining a particular rest of the simulation, the model has to be tested for its validity. Validity is the relationship among system, model and experiment frames. Zeigler et al. (2000, pp.25-33) have classified model validity into replicative (agreement of a model and the system within acceptable tolerance limit), predictive (the ability to predict unseen system behaviour) and structural (the ability to mimic when the system does its transition). Oakshott (1977, p. 133), however, has a different way of classifying the measures of model validity. According to his argument, face (capacity to replicate the real system), fit (adherence to the initial assumptions) and statistical tests are required to validate a model. Models can also be compared and selected based on their forecasting (predicting) precision (Franses and van Dijk, 2000).

However, the above discussion of model validation works only for simulations with real data, which helps us to check the validity of models against prior facts about the 
behavior of the data. In this simulation, no complete real data is used. Hence, the validating mechanism will be to compare variances from the expected mean of the final value. If SVA and NPV bars are the means of the expected final value for SVA and NPV respectively, the variance equations of the two models will be:

$$
\text { Variance }_{\mathrm{SVA}}=\frac{\sum_{\mathrm{i}=1}^{\mathrm{N}}\left(\mathrm{E}\left(\mathrm{SVA}_{\mathrm{i}}\right)-\overline{\mathrm{E}(\mathrm{SVA})}\right)^{2}}{\mathrm{~N}}
$$

(6) $\quad$ Variance $_{\mathrm{NPV}}=\frac{\sum_{\mathrm{i}=1}^{\mathrm{N}}\left(\mathrm{E}\left(\mathrm{NPV}_{\mathrm{i}}\right)-\overline{\mathrm{E}(\mathrm{NPV})}\right)^{2}}{\mathrm{~N}}$

In this analysis, the model with smaller variance is likely to have lower forecasting error of the expected final values. Following this argument, ten-year quarterly and semiannual observations are considered. Table 3 shows the descriptive statistics of the hypothetical data simulation. Accordingly, the NPV model has larger variance as compared to the SVA model. In addition, this variance seems increasing as the period changes from quarterly to semi-annually.

Table 3: Descriptive Statistics

\begin{tabular}{||l|r|c|r|r||}
\hline & \multicolumn{1}{|c|}{ Mean } & Median & Variance & \multicolumn{1}{c||}{ 90\% Confidence } \\
\hline NPV (Q) & $(165.7)$ & $(165.5)$ & 8.5 & $(165.5)-(162.3)$ \\
\hline SVA (Q) & 15.25 & 15.26 & 0.0001 & $15.27-15.28$ \\
\hline NPV (SA) & $(180.9)$ & $(184.6)$ & 16.2 & $(184.6)-(179.9)$ \\
\hline SVA (SA) & 5.41 & 5.46 & 0.001 & $5.42-5.34$ \\
\hline
\end{tabular}




\section{Sensitivity Analysis}

One of the objectives of this simulation is to investigate the sensitivity of the models to the final value. In order to perform this analysis, two value drivers are chosen: operating cost (OC) and the cost of capital (CC). These variables are found the most important drivers of shareholder value (Akalu, 2002b). The mean values of these drivers are considered to be $12 \%$ and $40 \%$ for $\mathrm{CC}$ and $\mathrm{OC}$ respectively. In this simulation, the two variables are assumed independent to each other. For the sensitivity analysis, ten-year life spans with quarterly and semiannual observations are considered. The base case scenario is the result discussed in section 4 . The following three alterative scenarios are constructed for analysis.

(a). Increase or decrease in either operating cost or cost of capital at the rate of $10 \%$ from the base case scenario.

(b). Simultaneous increase or decrease, in the same direction, in operating cost and cost of capital at the rate of $10 \%$ from the base case scenario.

(c). Simultaneous increase and decrease, in different direction, in operating cost and cost of capital at the rate of $10 \%$ from the base case scenario.

The value difference from the base case scenario is depicted in Table 4 and 5 . Referring to Table 4 [scenario (a)], the over all effect of operating cost is more significant compared to the effect of cost of capital. For this scenario, the SVA model is much more sensitive than the NPV model. In terms of observation period, all models are more sensitive to semiannual data than to the quarterly observations. 
Table 4: Independent move

(\% Changes from base case scenario)

Scenario [a]

\begin{tabular}{||c|r|r|r|r||}
\hline \multirow{2}{*}{$\begin{array}{c}\text { Model } \\
\text { (Frequency) }\end{array}$} & \multicolumn{2}{|c|}{ Cost of capital } & \multicolumn{2}{|c|}{ Operating cost } \\
\cline { 2 - 5 } & Increase & Decrease & Increase & Decrease \\
\hline NPV (Q) & $(1)$ & 18 & $(5)$ & 21 \\
\hline SVA (Q) & $(33)$ & 43 & $(73)$ & 73 \\
\hline NPV (SA) & $(9)$ & 9 & 16 & 12 \\
\hline SVA (SA) & $(96)$ & 124 & $(224)$ & 260 \\
\hline \hline
\end{tabular}

There are situations where we encounter changes in more than one variable at a time; thus, the impact of scenario [a] may not be the most likelihood case in real business. Hence, simultaneous moves may provide a better insight about the effect of variables and their changes across models. As can be observed from Table 5, both scenarios (b and c) reflect significant impacts of the change on the SVA model In the movement of opposite direction, the combination of the decline with $\mathrm{CC}$ and increase $\mathrm{OC}$ has over all negative impact on performance of company value. Similarly, the SVA is more sensitive under this scenario too. In addition, its relationship with operating cost is also much more important than the cost of capital.

Table 5: Simultaneous move

(\% Changes from base case scenario)

\begin{tabular}{||c|r|r|r|r||}
\hline \hline Models & \multicolumn{2}{|c|}{$\begin{array}{c}\text { Simultaneous } \\
\text { Same direction } \\
\text { Scenario [b] }\end{array}$} & \multicolumn{2}{c||}{$\begin{array}{c}\text { Simultaneous } \\
\text { Opposite direction } \\
\text { Scenario [c] }\end{array}$} \\
\cline { 2 - 5 } & Increase & Decrease & $\begin{array}{c}\text { +CC } \\
- \text { OC }\end{array}$ & $\begin{array}{r}-\mathrm{CC} \\
+\mathrm{OC}\end{array}$ \\
\hline NPV (Q) & $(13)$ & 31 & 11 & 4 \\
\hline SVA (Q) & $(93)$ & 133 & 27 & $(47)$ \\
\hline NPV (SA) & $(22)$ & 23 & 3 & $(4)$ \\
\hline SVA (SA) & $(300)$ & 440 & 100 & $(160)$ \\
\hline \hline
\end{tabular}

The criteria used to compare models facilities the selection of a model. If the variables under consideration are not controllable by the company operation, it is preferable to choose the less sensitive models. However, if the value drivers can be controlled with in reasonable degree, the sensitivity of a model is an advantage to control the movement of shareholder value. In the above discussion, the two value drivers are commonly known and 
are highly structured in any organization. In addition, they are the most important drivers of firm's value. Therefore, a model, which is sensitive to these value drivers, is preferable to properly manage the value of shareholders. Based on this argument, hence, SVA is the preferable.

\section{Discussions}

One of the hot debates in capital budgeting is the choice between free cash flow (value based management models) and DCF appraisal methods. In this regard, consultants in capital budgeting or project analysts favour more to the free cash flow models than the DCF appraisals techniques. However, the critic from the academics circle is in favour of the DCF methods. On the other hand, companies are increasingly using the free cash flow models in project valuations.

This simulation has witnessed the presence of variation between the performances of the DCF and free cash flow models. When these models are evaluated against the expected final value, the NPV is found less sensitive to the value driver changes and has larger cash flow forecast variation. Conversely, the SVA model is sensitive to operating costs and has small forecast variation. Hence, based on the analysis of this simulation, it can be concluded that the SVA model is more suitable for valuation than its rival. 
Appendix A

Initial values of the Simulation

(Hypothetical data)

\begin{tabular}{||l|l||}
\hline \hline Value Drivers & Values \\
\hline Mean cash flow & 100 \\
\hline Standard deviation & 0.05 \\
\hline OPC & $40 \%$ \\
\hline IRC & $30 \%$ \\
\hline IFC & $5 \%$ \\
\hline IWC & $15 \%$ \\
\hline Cost of capital & $12 \%$ \\
\hline Debt & 150 \\
\hline Cash flow from temporary investments & 0 \\
\hline \hline
\end{tabular}

Appendix B

Input from the SVA performance file

(Partially real data)

\begin{tabular}{||l|r|r|r|r||}
\hline & \multicolumn{3}{|c||}{ Sample Companies } \\
\hline \multicolumn{1}{|c|}{ Value driver } & High-01 & High-02 & Low-01 & \multicolumn{1}{c||}{ Low-02 } \\
\hline OPC & 0.42 & 0.43 & 0.31 & 0.41 \\
\hline IRC & 0.14 & 0.33 & 0.34 & 0.32 \\
\hline IFC & -0.13 & 0.01 & 0.28 & 0.05 \\
\hline IWC & -0.06 & -0.11 & -0.13 & 0.15 \\
\hline Debt (at market value) & 50 & 50 & 50 & 50 \\
\hline Cost capital & $12 \%$ & $12 \%$ & $12 \%$ & $12 \%$ \\
\hline Mean cash flow & 100 & 100 & 100 & 100 \\
\hline Standard deviation & 0.05 & 0.05 & 0.05 & 0.05 \\
\hline Cash flow from temporary & 0 & 0 & 0 & 0 \\
investments & & & & 0 \\
\hline
\end{tabular}




\section{References}

Akalu, M.M. (2002a). Evaluating the Capacity of Standard Investment Appraisal Methods: Evidence from the practice. Tinbergen Institute Discussion Paper Series (fourth coming), $1-14$.

Akalu, M.M. (2002b). Measuring and Ranking Value Drivers: A Shareholder Value Perspective. Tinbergen Institute Discussion Paper Series (Ref. TI- 2002-043/2), 1-17.

Brealey, R., and Myers, S. (2000). Principles of Corporate Finance. $6^{\text {th }}$ ed., McGraw Hill College Division, USA.

Eschenbach, T., and Smith, A. (1992). Sensitivity Analysis of EAC's Robustness. The Engineering Economist, 37(3), 263-276.

Finnegan, P. (1999). A Review of Shareholder Value Analysis and the Underlying Theory. The Henley Management Working Paper Series, (Ref. HWP 9803), 1-35.

Franses, P., and van Dijk, D. (2000). Nonlinear Time Series Models in Empirical Finance. Cambridge University Press.

Gitman, L. (1997). Principles of Managerial Finance. $8^{\text {th }}$ ed., Addison-Wesley, USA.

Hartman, J. (2000). Technical Note: on the equivalency of NPV and MVA as a measure of Project's economic worth. The Engineering Economist, 45(2), 158-165.

Kelliher, C., and Mahoney, L. (2000). Using Monet Carlo Simulation to Improve Long-Term Investment Decisions. The Appraisal Journal, 68(1), 44-56.

Kennedy, A. (2000). The End of Shareholder Value. Preseus Publishing, USA.

Mills, R. (1998). The Dynamics of Shareholder Value. Mars Business Associates Ltd., UK.

Mills, R., and Print, C. (1995). Strategic Value Analysis. Management Accounting, 73(2), 35-37.

Oakshott, L. (1977). Business Modeling and Simulation. Pitman Publishing, United Kingdom.

Rappaport, A. (1998). Creating Shareholder Value: A Guide for Managers and Investors. The Free Press, USA.

Sartori, D., and Smith, A. (1997). A Metamodel approach to sensitivity analysis of capital project valuation. The Engineering Economist, 43(1), 1-24.

Shubik, M., and Brewer, G. (1972). Models, Simulations and Games: A Survey (a report presented for Advanced Research Projects Agency. R-1060-ARPA/RC), California, USA. 
Shrieves, R., and Wachowicz, J. (2001). FCF, EVA, and NPV: A Reconciliation of Variations of the DCF valuation. The Engineering Economist, 46(1), 33-51.

Tully, S. (1993). The Real Key to Creating Wealth. Fortune, 128(6), 38-50.

Zeigler, B., Praehofer, H., and Kim, T. (2000). Theory of Modelling and Simulation. Academic Press, USA. 